\title{
SISTEM FUZZY METODE SAW PEMBERIAN BEASISWA PADA MAHASISWA STMIK TUNAS BANGSA BANDAR LAMPUNG
}

\author{
Alhibarsyah \\ STMIK Tunas Bangsa Bandar Lampung
}

\begin{abstract}
The scholarship is a form of giving the material, besides being able to encourage the students to be more active, to support the progress of the education world, to sharpen themselves to become a qualified student, and also to provide the relief in paying tuition fee for the students.STMIK Tunas Bangsa holds a scholarship program for outstanding and underprivileged students by fulfilling the requirements that must be met. This is where the campus conducts selection to determine who is eligible to receive the scholarship.In the process of selection of scholarship recipients is needed a method of decision-making scholarship. One of the methods that can be used for decision support systems is by applying the Fuzzy MADM (Multiple Attribute Decission Making) method. To perform the calculation on this method using SAW (Simple Additive Weighting) method. This method is chosen because it is able to select the best alternative from a number of alternatives, in this case the intended alternative is that eligible to receive scholarship based on the criteria specified.
\end{abstract}

Keywords : Scholarships, Fuzzy, SAW, Decisions, Criteria

\section{Pendahuluan}

Disetiaplembagapendidikankhusus nyaperguruan tinggi negeri ataupun swastabanyaksekalibeasiswa yang ditawarkankepadamahasiswa yang berprestasidan yang kurangmampu.Dalam hal ini beasiswa yang diberikan berasal dari Yayasan Pendidikan Tunas Bangsa melalui perguruan tinggi STMIK Tunas Bangsa.Untukmendapatkanbeasiswaterseb utharusmemenuhi kriteria dan persyaratan yang telahditetapkan. Kriteria yang ditetapkanoleh STMIK Tunas Bangsa adalahnilaiindeksprestasiakademik, penghasilan orang tua, jumlahsaudarakandung, jumlahtanggungan orang tua, semester danusia. Olehsebabitutidaksemua yang mendaftarkandirisebagaicalonpenerimabea siswatersebutakanditerima, hanya yang memenuhi criteria dan persyaratansaja yang akanmemperolehbeasiswatersebut.
Untuk mempermudah pemberian bea siswa dengan kriteria dan persyaratan melalui proses perangkingan yang sudah di tentukan dibuatlah suatu metode pengambilan keputusan untuk pemberian beasiswa yaitu dengan model Fuzzy Multiple AttributeDecision Making (FMADM)dan penghitungannya menggunakan metode SAW.

Dibuatnyametodepengambilankepu tusanpemberianbeasiswaakanterwujudnyat ransparansipemberianbeasiswadenganmen gintegerasikanperangkinganmahasiswadan memudahkanpengontrolanpemberianbeasi swa baik dari Yayasan, perguruan tinggi STMIK Tunas Bangsamaupun mahasiswa.

\section{TinjauanPustaka}

\section{Sistem Fuzzy}

Suatu sistem berbasis aturan fuzzy yang lengkap terdiri dari tiga komponen utama, yaitu : fuzzification, Inference, dan 
Defuzification. Fuzzification mengubah masukan-masukan yang nilai kebenarannya bersifat pasti (crisp input) ke dalam bentuk fuzzy input, yang berupa nilai linguistik yang semantiknya ditentukan berdasarkan fungsi keanggotaan tertentu. Inference melakukan penalaran menggunakan fuzzy input dan fuzzy rules yang telah ditentukan sehingga menghasilkan fuzzy output. Sedangkan Defuzification mengubah fuzzy output menjadi crisp value berdasarkan fungsi keanggotaan yang telah ditentukan. (Suyanto,2014).

\section{Beasiswa}

Padadasarnya,

beasiswaadalahpenghasilanbagi yang menerimanya.

Hal

inisesuaidenganketentuanpasal 4 ayat (1) UU

$\mathrm{PPh} / 2000$.

Disebutkanpengertianpenghasilanadalahta

mbahankemampuanekonomisdengannama

dandalambentukapa pun yang

diterimaataudiperolehdarisumber

Indonesia atauluar Indonesia yang dapatdigunakanuntukkonsumsiataumenam bahkekayaanWajibPajak

(WP).

Karenabeasiswabisadiartikanmenambahke mampuanekonomisbagipenerimanya, berartibeasiswamerupakanpenghasilan (JawaPos, 2009).

\section{FMADM}

Fuzzy Multiple Attribute Decision Making FMADM adalahsuatumetode yang digunakanuntukmencarialternatif optimal darisejumlahalternatifdengankriteriatertent u. Intidari FMADMadalahmenentukannilaibobotuntu ksetiapatribut,kemudiandilanjutkandengan proses perankingan yang akanmenyeleksialternatif yang sudahdiberikan. Padadasarnya, ada 3 pendekatanuntukmencarinilaibobotatribut, yaitupendekatansubyektif, pendekatanobyektifdanpendekatanintegras iantarasubyektif\&obyektif. Masingmasingpendekatanmemilikikelebihandank elemahan. Padapendekatansubyektif, nilaibobotditentukanberdasarkansubyektifi tasdari parapengambilkeputusan, sehinggabeberapafaktordalam proses perankinganalternatifbisaditentukansecara bebas.

Sedangkanpadapendekatanobyektif,nilaibo botdihitungsecaramatematissehinggameng abaikansubyektifitasdaripengambilkeputus an. (Kusumadewi, 2007).

Ada beberapametode yang dapatdigunakanuntukmnyelesaikanmasala h FMADM. antara lain (Kusumadewi, 2006):

a. Simple Additive Weighting Method (SAW)

b. Weighted Product (WP)

c. ELECTRE

d. Technique for Order Preference by Similarity to Ideal Solution (TOPSIS)

e. Analytic Hierarchy Process (AHP)

\section{Metode SAW (Simple Additive Weighting)}

Metode SAW (Simple

Additive Weighting)

seringjugadikenalistilahmetodepenjumlaha nterbobot. Konsepdasarmetode SAW adalahmencaripenjumlahanterbobotdari rating

kinerjapadasetiapalternatifpadasemuaatrib ut. Metode SAW membutuhkan proses normalisasimatrikskeputusan kesuatuskala yang dapatdiperbandingkandengansemua rating alternative yang ada.

$r_{i j}=\frac{x_{i j}}{\max _{\mathrm{i}} x_{i j}} \mathrm{jikaj}$

adalahatributkeuntungan (benefit)

$r_{i j}=\frac{\min _{i} x_{i j}}{x_{i j}}$ jika j adalahatributbiaya

(cost)

dimanar ${ }_{i j}$ adalah

rating

kinerjaternormalisasidarialternatif $\quad \mathrm{Ai}$ padaatributCj; $i=1,2, \ldots, m$ dan $j=1,2, \ldots, n$. 
Nilaipreferensiuntuksetiap alternative (Vi) diberikansebagai:

$$
\mathrm{V}=\sum_{j=1}^{n} w_{j} r_{i j}
$$

NilaiVi

yang

lebihbesarmengindikasikanbahwaalternatif Ai lebihterpilih.

\section{Sistem Pendukung Keputusan}

Sistem Pendukung Keputusan (SPK) atau Decision Support System (DSS) adalah sebuah sistem yang mampu memberikan kemampuan pemecahan masalah maupun kemampuan pengkomunikasian untuk masalah dengan kondisi semi terstruktur dan tak terstruktur. Sistem ini digunakan untuk membantu pengambilan keputusan dalam situasi semi terstruktur dan situasi yang tidak terstruktur, dimana tak seorangpun tahu secara pasti bagaimana keputusan seharusnya dibuat (Turban, 2001).

SPK bertujuan untuk menyediakan informasi, membimbing, memberikan prediksi serta mengarahkan kepada pengguna informasi agar dapat melakukan pengambilan keputusan dengan lebih baik.

SPK merupakan implementasi teoriteori pengambilan keputusan yang telah diperkenalkan oleh ilmu-ilmu seperti operation research dan menegement science, hanya bedanya adalah bahwa jika dahulu untuk mencari penyelesaian masalah yang dihadapi harus dilakukan perhitungan iterasi secara manual (biasanya untuk mencari nilai minimum, maksimum, atau optimum).

Sprague dan Watson mendefinisikan Sistem Pendukung Keputusan (SPK) sebagai sistem yang memiliki lima karakteristik utama yaitu (Sprague et.al, 1993):

1. Sistem yang berbasis komputer.

2. Dipergunakan untuk membantu para pengambil keputusan

3. Untuk memecahkan masalah-masalah rumit yang mustahil dilakukan dengan kalkulasi manual

4. Melalui cara simulasi yang interaktif
5. Dimana data dan model analisis sebagai komponen utama.

\section{Komponen Sistem Pendukung Keputusan}

Secara umum Sistem Pendukung Keputusan dibangun oleh tiga komponen besar yaitu database Management, Model Base dan Software System/User Interface. Komponen SPK tersebut dapat digambarkan seperti gambar di bawah ini.

\section{Manfaat Sistem Pendukung Keputusan}

SPK dapat memberikan berbagai manfaat dan keuntungan. Manfaat yang dapat diambil dari SPK adalah :

1. SPK memperluas kemampuan pengambil keputusan dalam memproses data / informasi bagi pemakainya.

2. SPK membantu pengambil keputusan untuk memecahkan masalah terutama barbagai masalah yang sangat kompleks dan tidak terstruktur.

3. SPK dapat menghasilkan solusi dengan lebih cepat serta hasilnya dapat diandalkan.

4. Walaupun suatu SPK mungkin saja tidak mampu memecahkan masalah yang dihadapi oleh pengambil keputusan, namun dia dapat menjadi stimulan bagi pengambil keputusan dalam memahami persoalannya,karena mampu menyajikan berbagai alternatif pemecahan.

\section{MetodologiPenelitian}

Metode FMADM (Fuzzy Multiple
Atribute Decision
Making)dapatmenenetukannilai-
nilaiterhadapindikatoryaitujumlahpenghasi
lanorangtua, semester,
jumlahtanggunganOrangtua, dannilai IPK.
Selanjutnyamasing- rang
masingindikatortersebutdianggapsebagaikr
iteria yang
akandijadikansebagaifaktoruntukmenentuk
anpenerimabeasiswa.


Selanjutnyaditentukanhimpunan

fuzzy sebagaipatokanpenentuanperingkat. HimpunanfuzzynyaadalahTinggi, Sedang, Tengah, Banyak, Rendah. Himpunaninikemudiandiperlakukansebaga $i$ input kedalamsistem FMADM (dalamhalinidisebutsebagiCi). Keluaran yang

dihasilkandaripenelitianiniadalahsebuahalt ernatif yang memilikinilaitertinggidibandingkandengan alternatifnilai yang lain. Padapenelitianinihasilkeluarannyadiambild ariurutanalternatiftertinggikealternatifteren dah. Hasilakhir yang dikeluarkanoleh program nantiberasaldarinilaisetiapkriteria, karenadalamsetiapkriteriamemilikinilai yang berbeda-beda. Urutanalternatif yang akanditampilkanmulaidarialternatiftertingg ikealternatifterendah.

Sedangkan untuk kriterianya terbagi dalam dua kategori yaitu untuk bernilai positif termasuk dalam kriteria keuntungan dan yang bernilai negatif termasuk dalam kriteria biaya.

$r_{i j}=\frac{x_{i j}}{\max _{\mathrm{i}} x_{i j}} \mathrm{jika} \mathrm{j}$

adalahatributkeuntungan (benefit)

$r_{i j}=\frac{\min _{i} x_{i j}}{x_{i j}}$ jika j adalahatributbiaya (cost)

Dimanar ${ }_{i j}$ adalah kinerjaternormalisasidarialternatif $\quad \mathrm{Ai}$ padaatributCj; $i=1,2, \ldots$, mdan $j=1,2, \ldots, n$.

Nilaipreferensiuntuksetiap alternative (Vi) diberikansebagai:

$$
V=\sum_{j=1}^{n} w_{j} r_{i j}
$$

NilaiVi yang

lebihbesarmengindikasikanbahwaalternatif Ai lebihterpilih.

Keterangan :

$$
\begin{aligned}
& \text { A : Alternatif } \\
& \text { C : Kriteria } \\
& \text { W : Bobot Preferensi }
\end{aligned}
$$

$$
\begin{aligned}
& \mathrm{V}: \text { Nilai preferensi untuk } \\
& \text { setiap alternatif } \\
& \mathrm{X} \text { : Nilai Alternatif dari } \\
& \text { setiap kriteria }
\end{aligned}
$$

\section{Tahapan Metode SAW}

1. Menentukan kriteria-kriteria yang akan dijadikan acuan dalam pengambilan keputusan, yaitu $\mathrm{C} 1$.

2. Menentukan rating kecocokan setiap alternatif pada setiap kriteria.

3. Membuat matriks keputusan berdasarkan kriteria (C1), kemudian melakukan normalisasi matriks berdasarkan persamaan yang disesuaikan dengan jenis atribut sehingga diperoleh matriks ternormalisasi $\mathrm{R}$.

4. Hasil akhir diperoleh dari proses perankingan yaitu penjumlahan dariperkalian matriks ternormalisasi $\mathrm{R}$ dengan vector bobot sehinggadiperoleh nilai terbesar yang dipilihsebagai alternatif terbaik (A1) sebagai solusi.

Adapun bobot kriterianya adalah:

a. $\mathrm{C} 1=$ Jumlah penghasilan Orangtua $(0,3)$

b. $\mathrm{C} 2=$ Semester $(0,1)$

c. $\mathrm{C} 3=$ Tanggungan Orangtua $(0,15)$

d. $\mathrm{C} 4=$ Nilai IPK $(0,45)$

Dari masing-masing bobot tersebut, maka dibuat suatu variabel-variabelnya. Dimana dari suatu variabel tersebut akan dirubah kedalam bilangan fuzzynya. Di bawah ini adalah bilangan fuzzy dari bobot.

1. Sangat Rendah ( SR $)=0$

2. $\operatorname{Rendah}(\mathrm{R})=0.2$

3. Sedang $(\mathrm{S})=0.4$

4. Tengah $(\mathrm{T})=0.6$

5. Tinggi $(\mathrm{TI})=0.8$

6. Banyak $(\mathrm{B})=1$

\section{Kriteria Penghasilan Orang Tua}

Variabel penghasilan orang tua dikonversikan dengan bilangan fuzzy dibawah 
Tabel 1. Penghasilan Orangtua

\begin{tabular}{|c|c|}
\hline Penghasilan Orang Tua (X) & Nilai \\
\hline $\mathrm{X}>=\mathrm{Rp} 10.000 .000$ & 0.25 \\
\hline $\mathrm{X}=\mathrm{Rp} 5.000 .000-10.000 .000$ & 0.5 \\
\hline $\mathrm{X}=\mathrm{Rp} 1.000 .000-5.000 .000$ & 0.75 \\
\hline $\mathrm{X}<=\mathrm{Rp} 1.000 .000$ & 1 \\
\hline
\end{tabular}

\section{Kriteria Semester}

Variabel semester di konversikan dengan bilangan fuzzy pada tabel semester untuk mahasiswa pada saat semester keberapa mahasiswa tersebut sedang aktif kuliah dibawah ini.

Tabel 2. Semester

\begin{tabular}{|c|c|}
\hline Semester $(\mathbf{X})$ & Nilai \\
\hline Semester 3 & 1 \\
\hline Semester 4 & 0.8 \\
\hline Semester 5 & 0.6 \\
\hline Semester 6 & 0.4 \\
\hline Semester 7 & 0.2 \\
\hline Semester 8 & 0 \\
\hline
\end{tabular}

\section{Kriteria Tanggungan Orangtua}

Variabel penghasilan orang tua dikonversikan dengan bilangan fuzzy pada

Tabel 3. Tanggungan Orangtua

\begin{tabular}{|c|c|}
\hline Tanggungan Orangtua (X) & Nilai \\
\hline 1 Anak & 0 \\
\hline 2 Anak & 0.25 \\
\hline 3 Anak & 0.5 \\
\hline 4 Anak & 0.75 \\
\hline 5 Anak & 1 \\
\hline
\end{tabular}

Kriteria IPK

Variabel nilai IPK dikonversikan dengan bilangan fuzzy pada tabel nilai IPK
Tabel Tanggungan orang tua terhadap jumlah anak yang dimiliki dibawah ini.

Tabel 4. IPK

\begin{tabular}{|c|c|}
\hline IPK $(\mathbf{X})$ & Nilai \\
\hline $\mathrm{IPK}<=2.75$ & 0 \\
\hline $\mathrm{IPK}=2.75-3.00$ & 0.25 \\
\hline $\mathrm{IPK}=3.00-3.25$ & 0.5 \\
\hline $\mathrm{IPK}=3.25-3.50$ & 0.75 \\
\hline $\mathrm{IPK}>=3.50$ & 1 \\
\hline
\end{tabular}

\section{Hasil dan Pembahasan}

Proses Penghitungan Seleksi Beasiswa mahasiswa tersebut yang layak pada saat mengajukan beasiswa dibawah ini. 
pemohon yang ingin mendaftarkan beasiswa dengan kriteria yang harus sudah ditentukan dari segi penghasilan orang tua, semester, tanggungan orang tua dan nilai IPK. Selengkapnya ada dalam table dibawah ini.

Tabel 5. Data Pemohon

\begin{tabular}{|l|l|c|c|c|c|}
\hline \multirow{2}{*}{ No } & Nama & \multicolumn{4}{|c|}{ Kriteria } \\
\cline { 3 - 6 } & & $\begin{array}{c}\text { Penghasilan } \\
\text { Orangtua }\end{array}$ & Semester & $\begin{array}{c}\text { Tanggungan } \\
\text { Orangtua }\end{array}$ & IPK \\
\hline 1 & Mahasiswa A & 5.000 .000 & 5 & 2 & 3.3 \\
\hline 2 & Mahasiswa B & 2.500 .000 & 3 & 3 & 3.5 \\
\hline 3 & Mahasiswa C & 3.000 .000 & 6 & 2 & 3.0 \\
\hline 4 & Mahasiswa D & 2.000 .000 & 7 & 4 & 3.2 \\
\hline 5 & Mahasiswa E & 2.500 .000 & 2 & 3 & 3.0 \\
\hline
\end{tabular}

Tabel 6. Data Pemohon Dalam Bilangan Fuzzy

\begin{tabular}{|l|l|c|c|c|c|}
\hline \multirow{2}{*}{ No } & \multirow{2}{*}{ Alternatif } & \multicolumn{4}{|c|}{ Kriteria } \\
\cline { 3 - 6 } & & $\mathbf{C 1}$ & $\mathbf{C 2}$ & $\mathbf{C 3}$ & $\mathbf{C 4}$ \\
\hline 1 & Mahasiswa A & 0,5 & 0,6 & 0,25 & 0,75 \\
\hline 2 & Mahasiswa B & 0,75 & 1 & 0,5 & 0,75 \\
\hline 3 & Mahasiswa C & 0,75 & 0,4 & 0,25 & 0,5 \\
\hline 4 & Mahasiswa D & 0,75 & 0,2 & 0,75 & 0,75 \\
\hline 5 & Mahasiswa E & 0,75 & 1 & 0,5 & 0,5 \\
\hline
\end{tabular}

Dari table diatas dapat dibentuk perhitungan secara matriks yang akan menghasilkan suatu keputusan $\mathrm{X}$ dari hasil pemrosesan bilangan fuzzy sebagai berikut :

$$
X=\left[\begin{array}{cccc}
0,5 & 0,6 & 0,25 & 0,75 \\
0,75 & 1 & 0,5 & 0,75 \\
0,75 & 0,4 & 0,25 & 0,5 \\
0,75 & 0,2 & 0,75 & 0,75 \\
0,75 & 1 & 0,5 & 0,5
\end{array}\right]
$$

Vektor bobot dari setiap kriteria yang sudah di tentukan

$\mathrm{W}=\left[\begin{array}{llll}0,3 & 0,1 & 0,15 & 0,45\end{array}\right]$

Nilai Maksimal Setiap kriteria :

\begin{tabular}{|l|l|}
\hline $\mathrm{K} 1$ & 0,75 \\
\hline $\mathrm{K} 2$ & 1 \\
\hline $\mathrm{K} 3$ & 0,75 \\
\hline $\mathrm{K} 4$ & 0,75 \\
\hline
\end{tabular}

Matriks ternormalisasi $\mathrm{R}$ diperoleh dari persamaan (2.1): a. Normalisasi Mahasiswa A

$$
\begin{aligned}
& R 1=\frac{0,5}{0,75}=0,67 \\
& R 2=\frac{0,6}{1}=0,6 \\
& R 3=\frac{0,25}{0,75}=0,34
\end{aligned}
$$

$R 4=\frac{0,75}{0,75}=1$ 
b. Normalisasi Mahasiswa B

$$
\begin{aligned}
& R 1=\frac{0,75}{0,75}=1 \\
& R 2=\frac{1}{1}=1 \\
& R 3=\frac{0,5}{0,75}=0,67 \\
& R 4=\frac{0,75}{0,75}=1
\end{aligned}
$$

c. Normalisasi Mahasiswa C

$$
\begin{aligned}
& R 1=\frac{0,75}{0,75}=1 \\
& R 2=\frac{0,4}{1}=0,4 \\
& R 3=\frac{0,25}{0,75}=0,34 \\
& R 4=\frac{0,5}{0,75}=0,67
\end{aligned}
$$

d. Normalisasi Mahasiswa D

$$
\begin{aligned}
& R 1=\frac{0,75}{0,75}=1 \\
& R 2=\frac{0,2}{1}=0,2 \\
& R 3=\frac{0,75}{0,75}=1 \\
& R 4=\frac{0,75}{0,75}=1
\end{aligned}
$$

e. Normalisasi Mahasiswa E

$$
R 1=\frac{0,75}{0,75}=1
$$

$$
\begin{aligned}
& R 2=\frac{1}{1}=1 \\
& R 3=\frac{0,5}{0,75}=0,67 \\
& R 4=\frac{0,5}{0,75}=0,67
\end{aligned}
$$

Selanjutnya dilakukan perkalian antara nilai normalisasi dengan nilai setiap kriteria atau nilai perfemsi $(\mathrm{V}=\mathrm{W} * \mathrm{R})$.Maka hasilnya adalah :
a. $(0,67 \times 0,3)+(0,6 \times 0,1)+(0,34 \times 0,15)$ $+(1 \times 0,45)=0,76$
b. $(1 \times 0,3)+(1 \times 0,1)+(0,67 \times 0,15)+$ $(1 \times 0,45)=0,9$
c. $(1 \times 0,3)+(0,4 \times 0,1)+(0,34 \times 0,15)+$ $(0,67 \times 0,45)=0,69$
d. $(1 \times 0,3)+(0,2 \times 0,1)+(1 \times 0,15)+(1$ $\mathrm{x} 0,45)=0,77$
e. $(1 \times 0,3)+(1 \times 0,1)+(0,67 \times 0,15)+$ $(0,67 \times 0,45)=0,8$

\section{Kesimpulan}

Dari hasil pengujian metode Fuzzy SAW ini, didapat kesimpulan bahwa:

1. Untuk pengambilan keputusan dengan metode Fuzzy SAW dipilih dari nilai perfemsi tertinggi.

2. Mahasiswa B lebih layak menerima beasiswa karena nilai perfemsinya lebih tinggi dibandingkan empat mahasiswa lainnya.

3. Adanya penambahan kriteria sehingga mahasiswa yang terseleksi akan lebih akurat.

\section{Daftar Pustaka}

Wiwi Verina, Yudhi Andrian, Iwan

Fitrianto Rahmad. Penerapan Metode Fuzzy Saw Untuk Penerimaan Pegawai Baru (Studi Kasus : STMIK Potensi Utama). Jurnal Ilmiah 
SISFOTENIKA. Vol. 5, No. 1, Januari 2015.

Alfa Saleh, Ria Eka Sari, Harris

Kurniawan. Metode Fuzzy Simple Additive Weighting (SAW) Dalam Menentukan Kualitas Kulit Ular Untuk Kerajinan Tangan (Studi Kasus : CV. Asia Exotica Medan). STMIK Potensi Utama. Seminar Nasional Informatika 2014.

Apriansyah Putra, Dinna Yunika

Hardiyanti. Penentuan Penerima Beasiswa Dengan Menggunakan Fuzzy Multiple Atribute Decission Making. Jurnal Sistem Informasi (JSI), VOL. 3, NO. 1, April 2011, ISSN Print : 20851588. ISSN Online : 2355-4614. Halaman 286-293. Jurusan Sistem
Informasi Fakultas Ilmu Komputer Universitas Sriwijaya Kusumadewi, Sri. 2013, Aplikasi Logika Fuzzy untuk Pendukung Keputusan, Yogyakarta, Graha Ilmu.

Sparague, R. H. and Watson H. J. 1993. Decision Support Systems: Putting Theory Into Practice. Englewood Clifts, N. J., Prentice Hall.

Turban, Efraim \& Aronson, Jay E. 2001. Decision Support Systems and Intelligent Systems. 6th edition. Prentice Hall: Upper Saddle River, NJ. 